\title{
A Prediction Method for Speech Audibility Taking Account of Hearing Loss Due to Aging Under Meaningless Noise
}

\author{
Takahiro Tamesue \\ Organization for Academic Information, Yamaguchi University \\ Japan
}

\section{Introduction}

Securing good transmission characteristics for speech information and achieving a comfortable sound environment in buildings used by a great variety of people in public city spaces, to say nothing of spaces used for intellectual or mental work such as schools and offices, comprise two of the most important problems of environmental design. A common method for evaluating listening scores and psychological impressions for audio signal has been discussed previously (Tamesue T. et al., 2003). However, this research paid attention only to subjects in their twenties with normal hearing, and as a result the relationships between the frequency characteristics of hearing loss due to factors such as aging and the listening scores for audio signals and the psychological impressions related to speech audibility were not considered. Taking this into consideration, this chapter considers how the listening scores of audio signals and the psychological impressions for speech audibility change while taking into account the effects of hearing loss due to factors such as aging. Specifically, frequency filters for simulating hearing loss are first prepared. Next, psychological listening experiments are conducted in which both the audio signal and the noise passing through the above-mentioned filters are transmitted to subjects with normal hearing. Using the observed experimental data, the relationships between the weight-mean spectral distance (Tamesue T. et al., 2003) and the listening scores of the audio signals and psychological impressions with respect to speech audibility are investigated. Next, based on these relationships, problems associated with the prediction of listening scores and psychological impressions with respect to speech audibility are discussed.

\section{Outline of psychological listening experiment I}

Psychological listening experiment I was conducted to establish the regression models of the listening scores of the audio signal and the psychological impressions related to speech audibility. The outline of the indoor experiment is as follows.

\subsection{Location}

The experiment was conducted in a simple soundproof room on campus having the following dimensions: length $5.1 \mathrm{~m}$, width $3.3 \mathrm{~m}$, and height $2.2 \mathrm{~m}$. The sound pressure level of the background noise was about $37 \mathrm{~dB}$. The sound pressure level in this chapter is the value measured by a sound level meter with FLAT response. The A-weighted sound pressure level was about $21 \mathrm{~dB}(\mathrm{~A})$. 


\subsection{Subjects}

A total of 8 students, 7 male and 1 female, all in their 20s with normal hearing, participated in the psychological listening experiment.

\subsection{Presented sound}

\subsubsection{Audio signal}

A monosyllable list (a list containing 50 monosyllables) from a CD originally designed for the evaluation and fitting of hearing aids (TY-89) (Yonemoto K., 1995) was used. The maximum band levels of speech were measured with a real-time octave-band analyzer. Maximum band levels were adopted as the band levels of the speech peaks. The over-all sound pressure level of the speech peaks was about $62 \mathrm{~dB}$.

\subsubsection{External noise}

The external noise consisted of band-limited pink noise with frequency bandwidth $[44,11,300]$ Hz. The sound pressure level in each subject's ears was adjusted to $44,47,50,53,56,59,62$, $65,68,71,74$, and $77 \mathrm{~dB}$.

It is well known that hearing acuity declines with age. Moreover, several studies have reported on the frequency characteristics of hearing loss associated with aging (ISO7029, 1984) (Yokouchi Y., 1967). Taking into account the frequency characteristics of such hearing loss (Yokouchi Y., 1967), both the audio signal and noise were passed through frequency filters A, B, C, and D to simulate hearing loss experienced by individuals in their 20s, 50s, 70s and 80s based on their 20s. The frequency characteristics of the filters are shown in Figure 1. There is a tendency for the overall sound pressure level to decrease and for the higher frequency to attenuate in the following order: A, B, C, D.

\subsection{Measurement of listening scores and psychological impressions}

Both the audio signal and noise were presented to the eight subjects through two speaker boxes to allow assessment of the listening scores of the audio signal and the psychological impressions associated with speech audibility while listening to the audio signal. It was confirmed prior to the experiment that there was no difference in the sound pressure levels at the subjects' ears. To quantify the psychological evaluation of speech audibility, various psychological evaluation scales for audio signals were considered. For this experiment, the seven categorized psychological impressions $A_{i}(i=1,2, \ldots, 7)$ of speech audibility (Nakajima T. et al., 1984) were adopted:

$$
\begin{aligned}
& A_{1}: \text { Very inaudible } \\
& A_{2}: \text { Quite inaudible } \\
& A_{3}: \text { Slightly inaudible } \\
& A_{4}: \text { Medium }
\end{aligned}
$$

$$
\begin{aligned}
& A_{5}: \text { Slightly audible } \\
& A_{6}: \text { Quite audible } \\
& A_{7} \text { : Very audible }
\end{aligned}
$$

The eight subjects participated simultaneously in the psychological listening experiment. They listened to the audio signal and completed a response sheet asking them to report exactly what they had heard. In addition, they performed the above psychological evaluation, i.e., $A_{i}$ $(i=1,2, \ldots, 7)$, related to speech audibility. This operation was then carried out with the same subjects for an external noise condition as well. The subjects were given sufficient rest to avoid fatigue. 


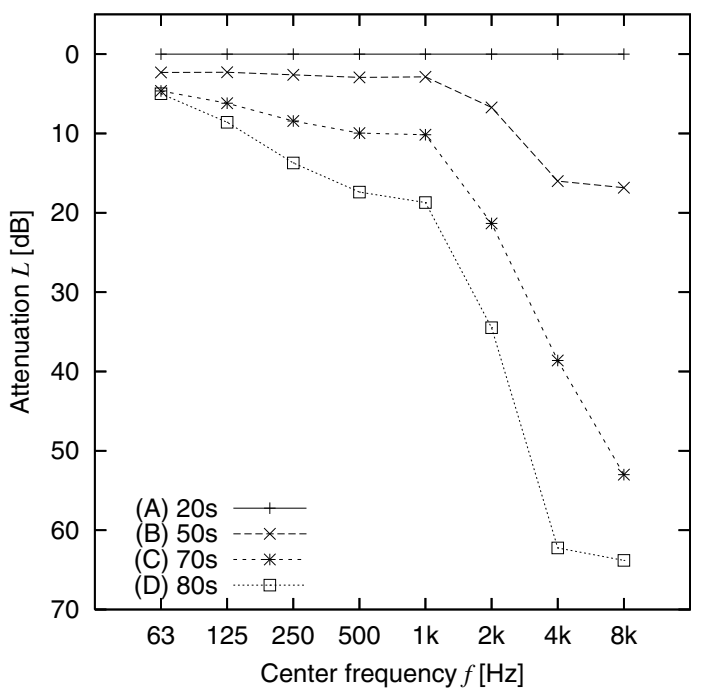

Fig. 1. Frequency characteristics of simulated hearing loss by filter (A: 20s, B: 50s, C: 70s, D: $80 \mathrm{~s})$

\section{Relationships between index and listening scores / psychological impressions}

\subsection{Index for evaluating listening scores and psychological impressions}

In our previous research (Tamesue T. et al., 2003), the most useful indexes for evaluating the listening scores of audio signals and psychological impressions as they relate to speech audibility under conditions of meaningless steady noise while listening to an audio signal were investigated. The results indicated that weighted-mean spectral distance WSPD was the most useful target index. We therefore used the same index in this study. WSPD was calculated as follows:

$$
W S P D=\sum_{i=1}^{8} a_{i}\left[L_{S}\left(f_{i}\right)-L_{N}\left(f_{i}\right)\right]
$$

where $a_{i}$ denotes the weight considered to be percentages of 20 frequency bands(Kryter KD., 1962) that contribute equally to speech intelligibility. These are included in octave bands with center frequency $f_{i}\left(f_{1}=63, f_{2}=125, \cdots, f_{8}=8000 \mathrm{~Hz}\right)$, and are shown as follows:

$$
\begin{array}{llll}
a_{1}=0.000000 & a_{2}=0.000000 & a_{3}=0.063794 & a_{4}=0.140096 \\
a_{5}=0.226255 & a_{6}=0.319855 & a_{7}=0.227360 & a_{8}=0.022640
\end{array}
$$

$L_{S}\left(f_{i}\right)$ denotes the band level with center frequency $f_{i}\left(f_{1}=63, f_{2}=125, \cdots, f_{8}=8000 \mathrm{~Hz}\right)$ of the speech peaks. In this, the maximum band levels of the audio signal, measured by a sound level meter (RION, type NL-22) along with a real-time octave-band analyzer (RION, type NX-22RT) with FAST dynamic response for 180 seconds, are adopted as the band levels of the speech peaks. $L_{N}\left(f_{i}\right)$ denotes the band level with center frequency $f_{i}$ of the noise. These band levels were measured by the real-time octave-band analyzer built into the sound level meter with FAST dynamic response. 


\subsection{Relationship between $W S P D$ and the listening score of the audio signal}

The subjects noted the monosyllables exactly as they heard them, as described in 2.4. The number of correct answers given by each subject was assessed, with the listening score for the audio signal being defined as the percentage of correct monosyllables from the total (50). Using the observed data obtained during psychological listening experiment I, the relationship between WSPD and the listening scores of the audio signal were examined. In order to understand this relationship, the following models describing the regression between them were adopted.

Linear function:

$$
y=a x+b
$$

Logistic function:

$$
y=\frac{k-c}{1+a \exp (-b x)}+c
$$

Gomperz function:

$$
y=(k-c) \exp (-\exp (-a(x-b)))+c
$$

In each case both the audio signal and noise passed through one of the frequency filters, $A, B$, $\mathrm{C}$, or $\mathrm{D}$, and the relationship between WSPD and the listening score of the audio signal was calculated. These results are shown in Figure 2. The lines in the figure indicate the regression line as selected by AIC (Akaike H., 1974).

Here, the expressions are represented by eqn.(5). This figure reveals the following: when the value of WSPD decreased, the listening score of the audio signal approached 0 . This indicates that when there is a larger level of hearing loss, the listening score of the audio signal clearly decreases.

\subsection{Relationship between WSPD and psychological impressions related to speech audibility}

The relationships between WSPD and the psychological impressions related to speech audibility were investigated using frequency filters A, B, C, D in the same way as the above investigation of the listening scores of the audio signal. Figure 3 shows the results of the regression models represented by eqn.(5), which was found to be the most suitable. In Figure 3, when the value of WSPD decreased, the psychological impression related to speech audibility approached $A_{1}$. This indicates that the psychological impression related to speech audibility decreases with a reduction of hearing acuity.

\section{Outline of psychological listening experiment II}

Psychological listening experiment II was conducted to compare the observed values of the listening scores of the audio signal and the psychological impressions related to speech audibility with the predicted values. This experiment was conducted as follows.

\subsection{Subjects}

A total of 24 students, 20 male and 4 female, all in their 20s with normal hearing, participated in psychological listening experiment II. These subjects were different from the subjects who participated in psychological listening experiment I. 


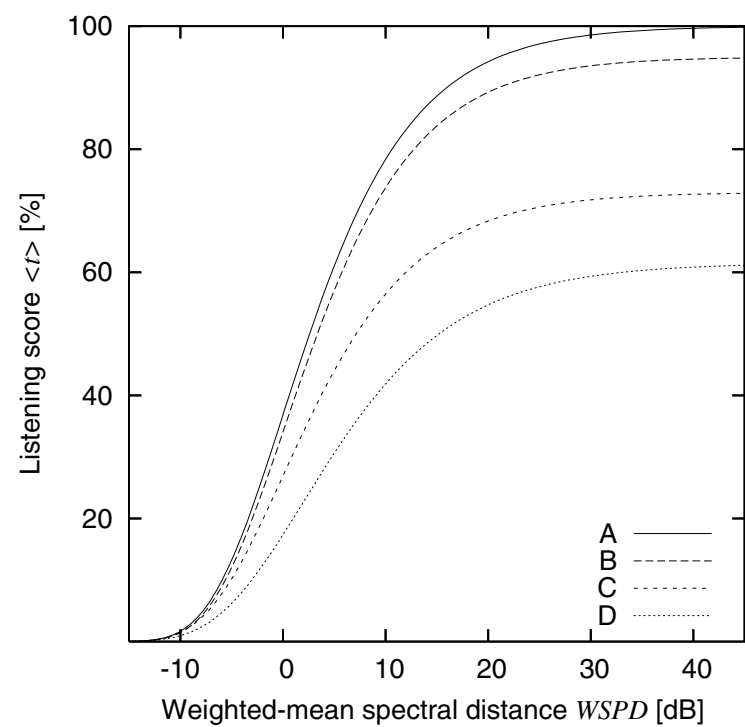

Fig. 2. Relationship between the listening score of the audio signal and the weighted-mean spectral distance (A: 20s, B: 50s, C: 70s, D: 80s)

\subsection{Location}

The experiment was conducted in a soundproof room on campus having the following dimensions: length $3.0 \mathrm{~m}$, width $3.0 \mathrm{~m}$, and height $1.9 \mathrm{~m}$. The sound pressure level of the background noise was about $36 \mathrm{~dB}$. The A-weighted sound pressure level was about $20 \mathrm{~dB}(\mathrm{~A})$.

\subsection{Audio signal}

The same audio signal used in psychological listening experiment I

\subsection{External noise}

In order to best simulate an actual noise environment, various realistic external noises that contained many frequency components were used. The following two noises were adopted as examples of steady noise.

(a) Voice noise

A voice noise from a CD originally designed for the evaluation and fitting of hearing aids (TY-89) was used. The sound pressure level was adjusted to 57, 62, and $67 \mathrm{~dB}$.

(b) Road traffic noise

This consisted of pink noise whose power spectrum closely resembled that of actual road traffic noise. The sound pressure level was adjusted to 57, 62, and $67 \mathrm{~dB}$.

The following three noises were adopted as examples of a typical irregular fluctuating noise. 


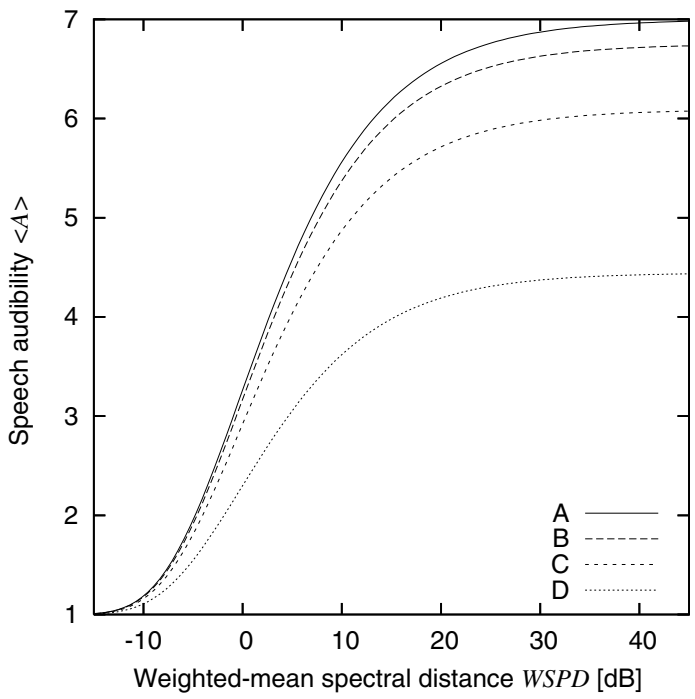

Fig. 3. Relationship between the psychological impressions related to speech audibility and weighted-mean spectral distance (A: 20s, B: 50s, C: 70s, D: 80s)

(c) Non-stationary road traffic noise

Actual road traffic noise under interrupted traffic flow conditions, recorded in advance for approximately two hours at the side of a road. The equivalent continuous sound pressure level was adjusted to 62 and $67 \mathrm{~dB}$.

(d) Stationary road traffic noise

Actual road traffic noise under uninterrupted traffic flow conditions obtained from the "Audio/Acoustics Technical CD for Professional Use." The equivalent continuous sound pressure level was adjusted to 62 and $67 \mathrm{~dB}$.

(e) Aircraft noise

Actual aircraft noise during take off obtained from the "Audio/Acoustics Technical CD for Professional Use." The equivalent continuous sound pressure level was adjusted to 62 and $67 \mathrm{~dB}$.

In addition, the following condition for predicting the listening score of the audio signal and psychological impressions related to speech audibility was used.

(f) No external noise

Similar to psychological listening experiment $\mathrm{I}$, both the audio signal and the noise were passed through frequency filters $\mathrm{A}, \mathrm{B}, \mathrm{C}$, and D.

\subsection{Measurement of listening scores and psychological impressions}

The specific method of measurement of the listening score of the audio signal and psychological impressions related to speech audibility was the same as that used in psychological listening experiment I. 


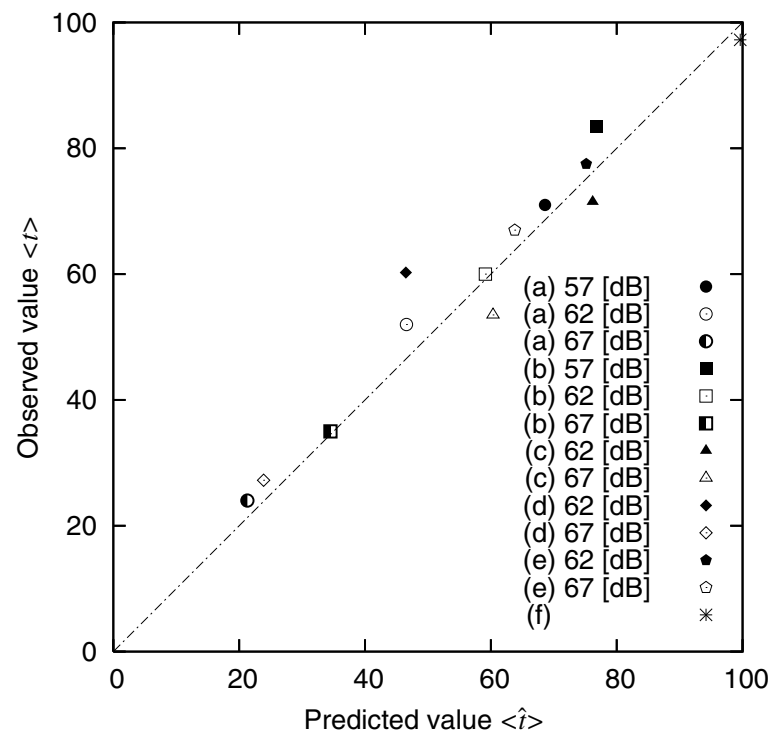

(a) Listening score

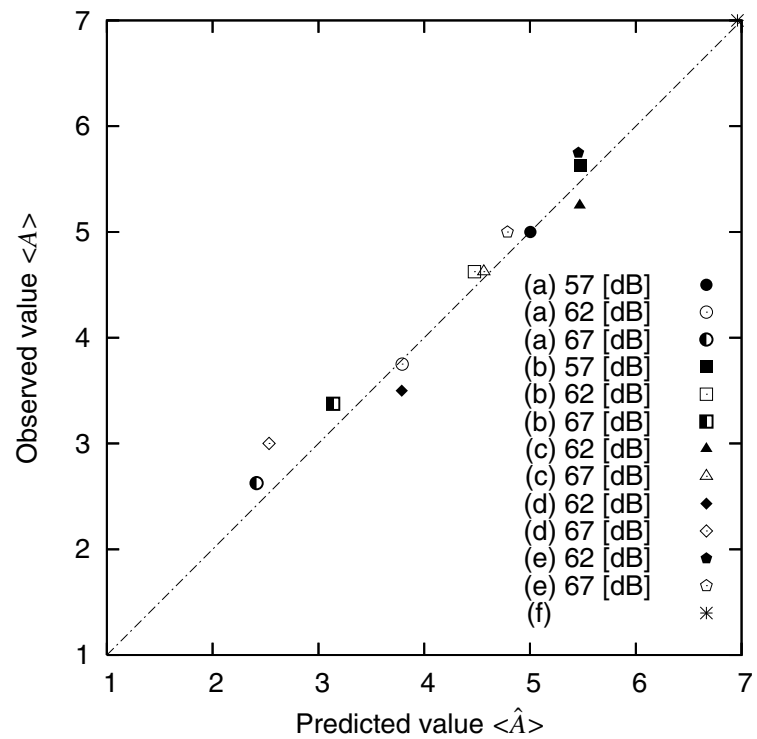

(b) Speech audibility

Fig. 4. Comparisons between the predicted and observed values (Frequency filter: A) 


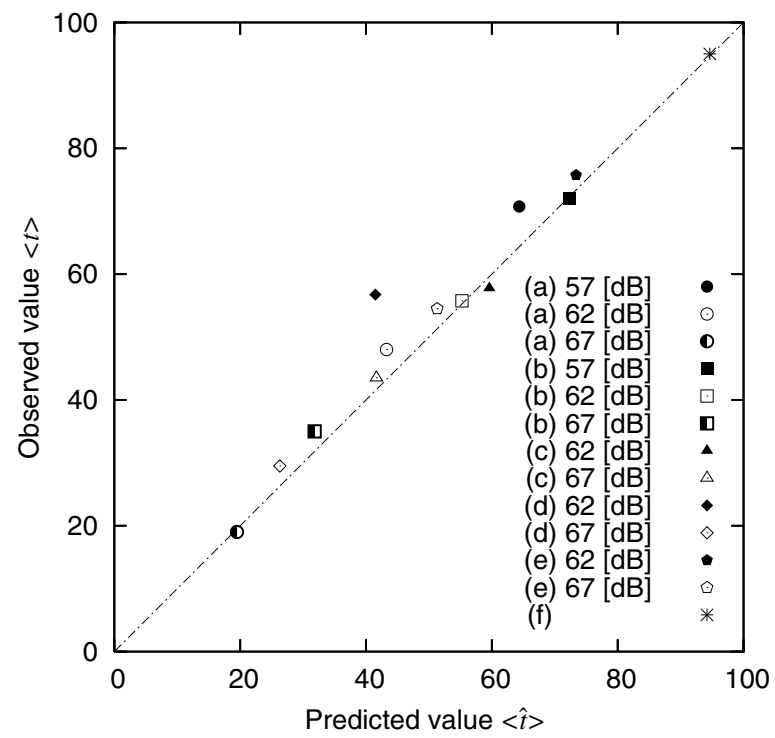

(a) Listening score

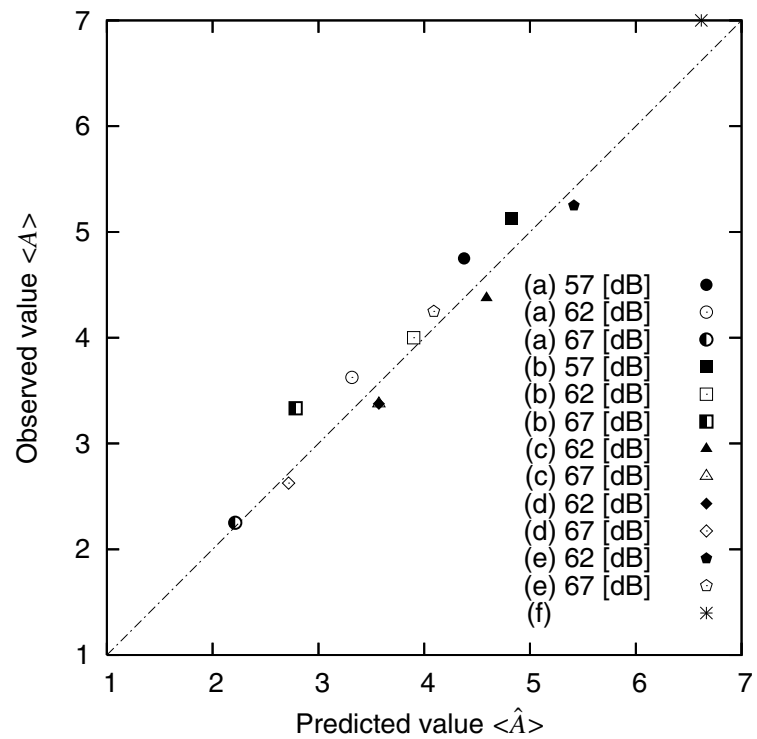

(b) Speech audibility

Fig. 5. Comparisons between the predicted and observed values (Frequency filter: B) 


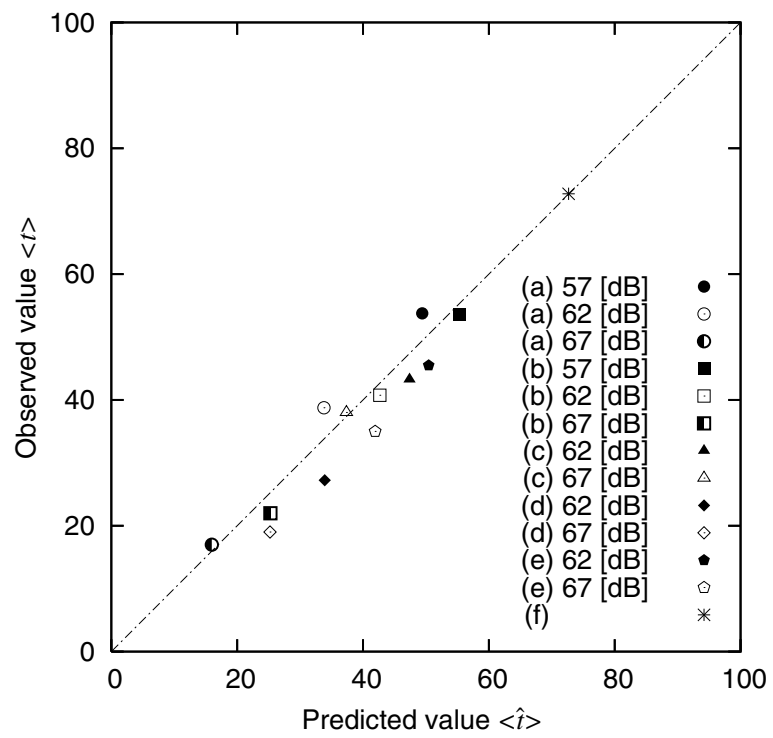

(a) Listening score

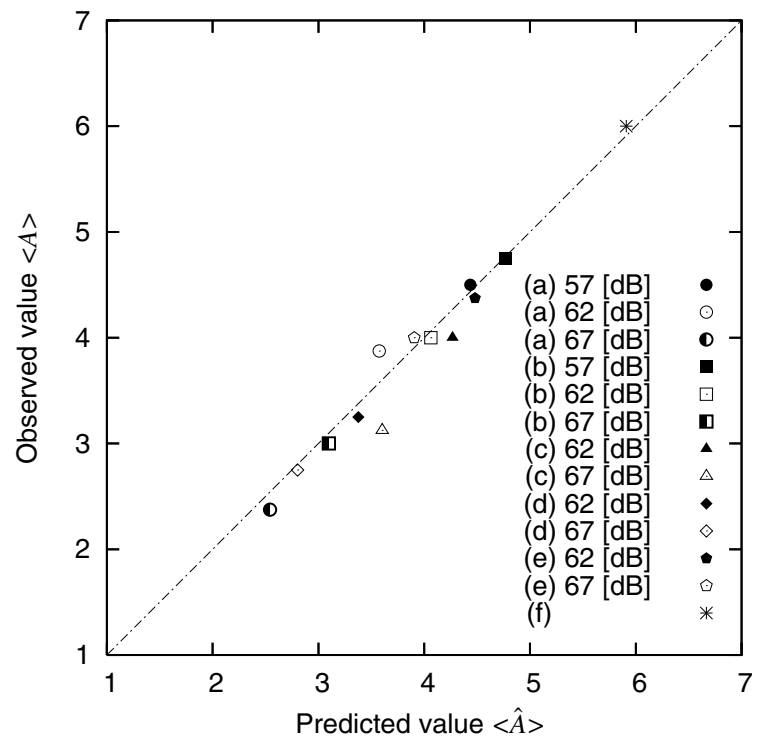

(b) Speech audibility

Fig. 6. Comparisons between the predicted and observed values (Frequency filter: C) 


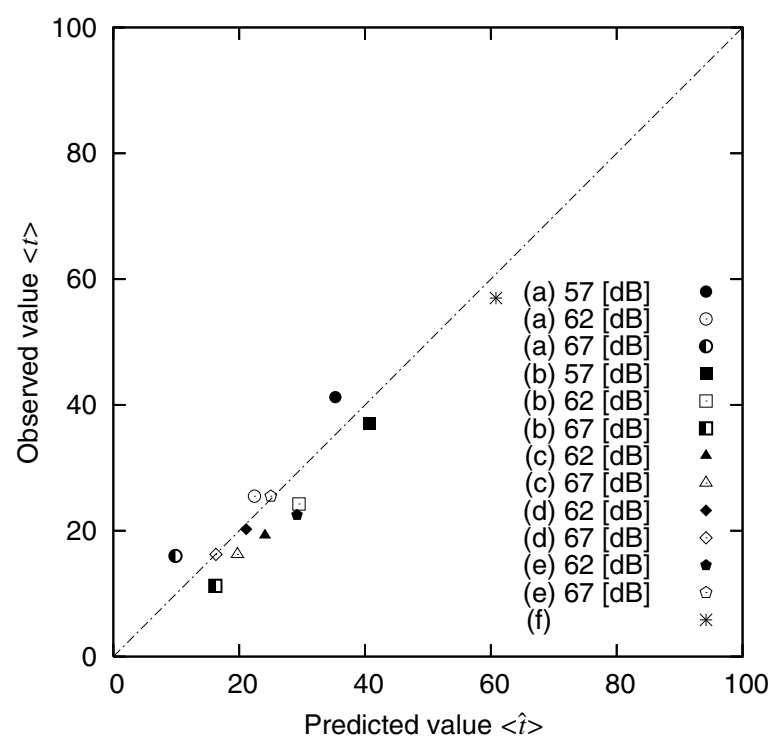

(a) Listening score

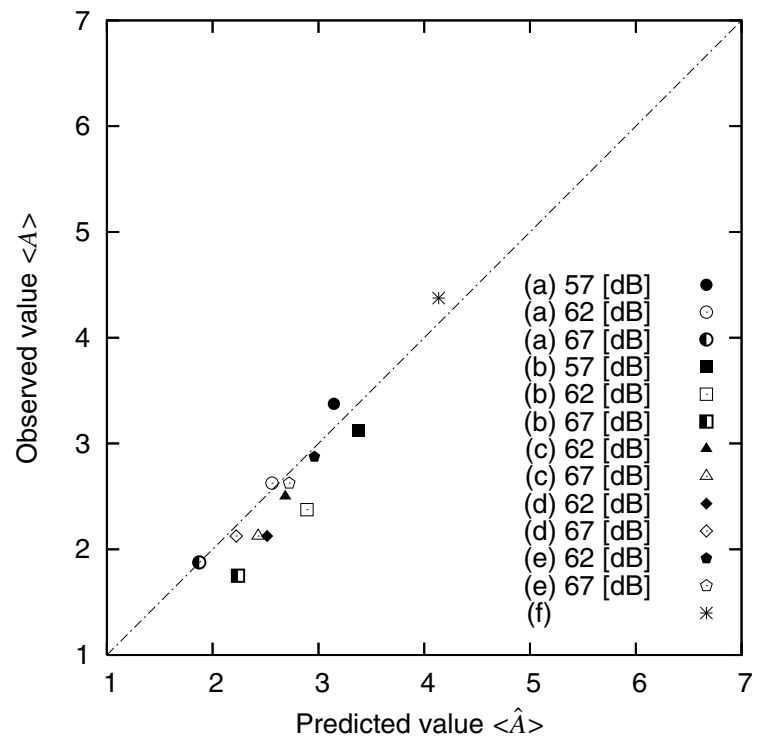

(b) Speech audibility

Fig. 7. Comparisons between the predicted and observed values (Frequency filter: D) 


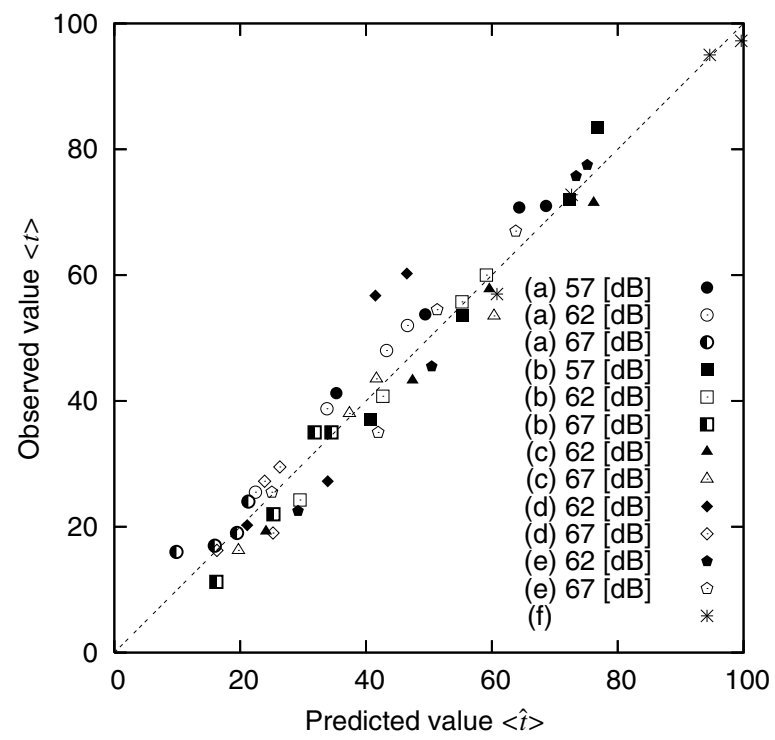

(a) Listening score

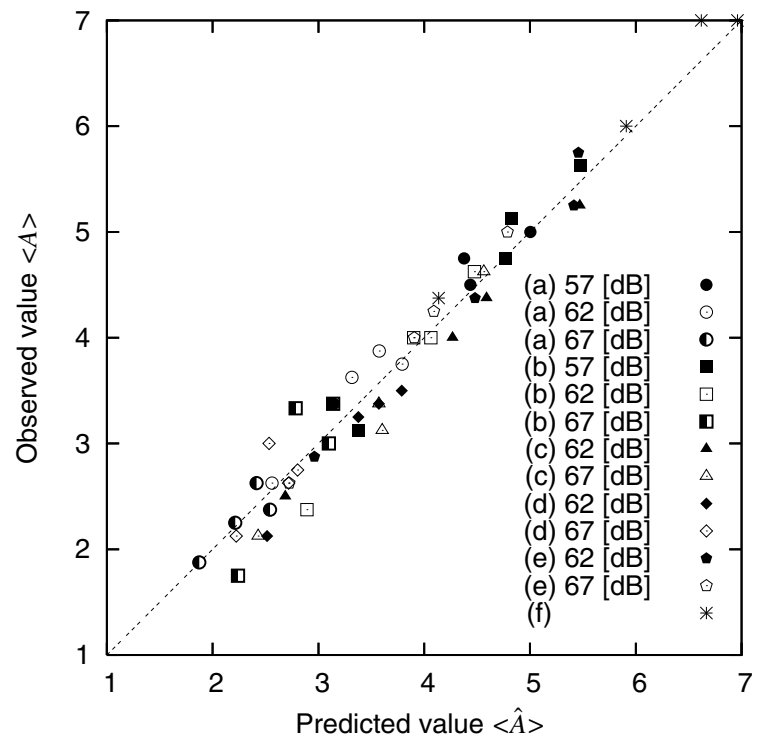

(b) Speech audibility

Fig. 8. Comparisons between the predicted and observed values 


\section{Prediction of listening scores and psychological impressions}

Employing the regression model shown in Figures 2 and 3, it was predicted that the listening scores of the audio signal and the psychological impressions related to speech audibility would change depending on actual noise environment. The subjects were exposured to the meaningless steady or fluctuating noise, with various power spectral level forms and sound pressure levels.

The value of WSPD were calculated for each noise condition (a) and (b). Using Figures 2 and 3, the theoretical predicted values of the listening scores of the audio signal were estimated for each noise condition (a) and (b). These were compared with the values obtained directly from the recorded data in psychological listening experiment II. As an example of the predictin results, comparisons between the predicted and observed values of the listening score of the audio signal when using frequency filter $\mathrm{A}$, which simulated the hearing loss experienced by individuals in their 20s, are shown in Figure 4(a). It can be seen from this figure that the predicted results are consistent with the observed values. In addition, the results from using frequency filter $\mathrm{B}, \mathrm{C}$, and $\mathrm{D}$, which simulated the hearing loss experienced by individuals in their 50s, 70s, and 80s, are shown in Figure 5(a), Figure 6(a) and Figure 7(a). The predicted values are in good agreement with the observed values shown in these figures, which become smaller than those in Figure 4(a). Finally, Figure 8(a) shows the results for all of the frequency filters (A, B, C, and D). Since the predicted values are in good agreement with the observed values, both the validity and the applicability of the proposed method were confirmed experimentally.

With respect to the psychological impressions associated with speech audibility, the theoretical predicted values were calculated for each of the noise conditions (a) and (b) using the regression models. As examples of the results, comparisons between the predicted and observed values of the psychological impressions associated with speech audibility when using frequency filters A, B, C, and D are shown in Figures 4(b), 5(b), 6(b) and 7(b), respectively. In these figures, a high level of consistency can also be seen between the predicted and observed values. Figure 8(b) shows the results for all of the frequency filters (A, B, C, D). Since the predicted values are in good agreement with the observed values similar to the listenig scores of audio signal, reasonable results were obtained.

Since WSPD is reflected in the mutual relationship between the spectral level of the speech peaks and that of noise, which is limited to steady noise with no fluctuations in sound pressure level or frequency components, it is not reasonable to evaluate the listening scores of the audio signal or the psychological impressions related to speech audibility in an actual noise environment where the sound pressure levels and frequency components of noise show an irregular fluctuation over time.

Thus, here we introduce the new index as instantaneous spectral distance ISPD, which reflects the relationship between the spectral level of the speech peaks and that of noise within a short time scale based on the WSPD. ISPD can be calculated as follows:

$$
I S P D=\sum_{i=1}^{8} a_{i}\left[L_{S}\left(f_{i}\right)-L_{N}^{\prime}\left(f_{i}\right)\right]
$$


where $a_{i}$ and $L_{S}\left(f_{i}\right)$ are the same as those of eqn.(1). $L_{N}^{\prime}\left(f_{i}\right)$ denotes the band level with center frequency $f_{i}\left(f_{1}=63, f_{2}=125, \cdots, f_{8}=8000 \mathrm{~Hz}\right)$ of the noise within a short time scale, measured with FAST dynamic response and a sampling frequency of $10 \mathrm{~Hz}$.

When the sound pressure levels and frequency components of noise show an irregular fluctuation over time, ISPD is a random variable. If regression models $f_{t}(I S P D)$ and $f_{A}(I S P D)$ of the listening score of the audio signal and psychological impressions associated with speech audibility (based on ISPD) and a probability density function $p(I S P D)$ on $I S P D$ are known, the averages of the listening scores of the audio signal and psychological impressions related to speech audibility can be calculated as follows:

$$
<*>=\int_{D} f_{*}(I S P D) p(I S P D) d I S P D \quad(D=[-40,40] \mathrm{dB})
$$

where* denotes $t$ and $A$ in the case of the listening scores of the audio signal and psychological impressions associated with speech audibility.

Here, the regression model to the listening score of audio signal and psychological impression for speech audibility based on ISPD, and the probability density function of ISPD for each noise condition were employed. From a practical point of view, $f_{t}(W S P D)$, shown in Figure 2, and $f_{A}(W S P D)$, shown in Figure 3 , were adopted as $f_{t}(I S P D)$ and $f_{A}(I S P D)$.

The probability distribution was obtained for each presented sound of the psychological listening experiment. Figures 9 and 10 show examples of the results in the case of noise (c)(62 $\mathrm{dB}$ ) using frequency filter $\mathrm{A}, \mathrm{B}, \mathrm{C}$, and $\mathrm{D}$ (which simulated the hearing loss experienced by individuals in their 20s, 50s, 70, 80s), respectively. Comparing these figures, it can be seen that probability distribution is translated in the direction of a higher level, and the spread of the values of ISPD is relatively small, caused by hearing loss due to factors such as aging.

The predicted values of the listening score of the audio signal were calculated from eqn.(7) with the probability distribution obtained for each fluctuating noise condition. As an example of these results, comparisons between the predicted and observed values of the listening scores of the audio signal for each of the fluctuating noise conditions (c), (d), and (e) when using frequency filter A are shown in Figure 4(a). Even in an actual noise environment, the predicted values are in good agreement with the observed values. The results obtained when using frequency filter B, C, and D are shown in Figure 5(a), Figure 6(a), and Figure 7(a), respectively. Finally, the results from using all of the frequency filters (A, B, C, D) are shown in Figure 8(a). Since the predicted values of the listening score of audio signal by use of ISPD are in good agreement with the observed values, both the validity and the applicability were confirmed in fluctuating noise environment.

In addition, the predicted values of the psychological impressions associated with speech audibility were calculated for each of the fluctuating noise conditions of (c), (d), and (e) using eqn.(7). Comparisons between the predicted and observed values of the psychological impression associated with speech audibility when using frequency filters A, B, C, and D are shown in Figures 4(b), Figure 5(b), Figure 6(b), and Figure 7(b), respectively. The results from using all of the frequency filters (A, B, C, D) are shown in Figure 8(b). Even the predicted values of the the psychological impressions associated with speech audibility by use of ISPD are in good agreement with the observed values. It is possible to predict a psychological impressions associated with speech audibility as a whole over a long period of time, after a certain amount of exposure to noise. 


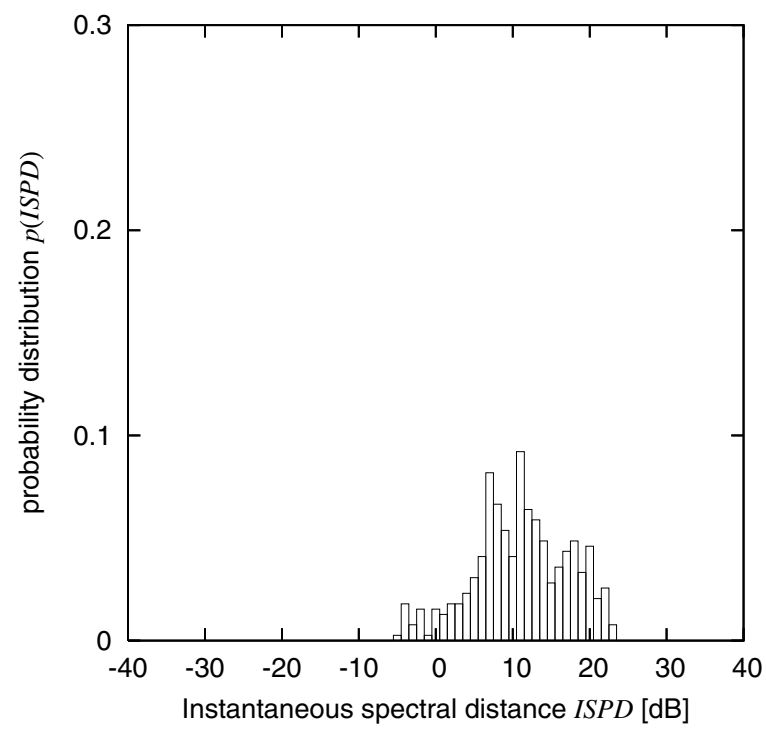

(a) Frequency filter: A

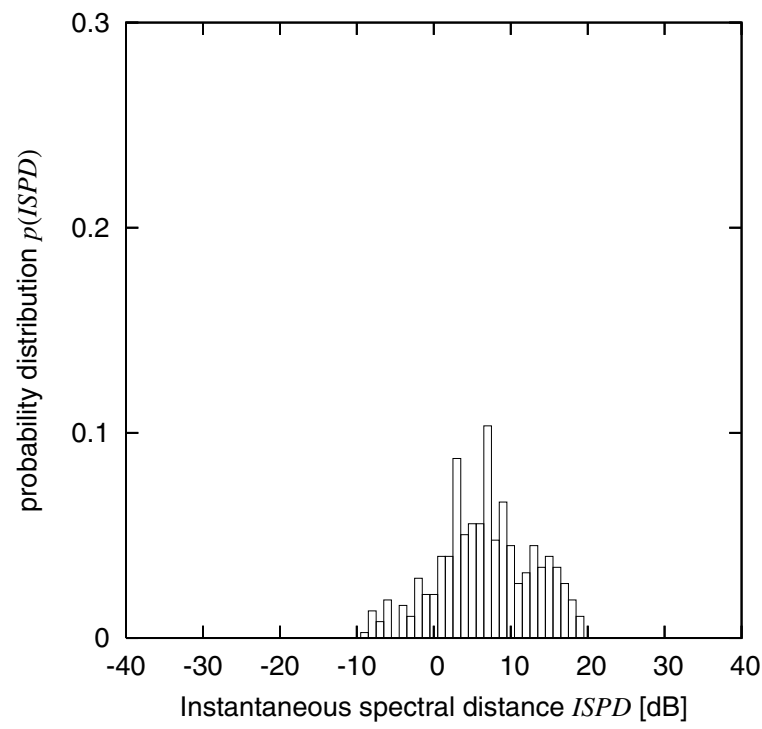

(b) Frequency filter: B

Fig. 9. Probability distribution on instantaneous spectral distance ((c) $62 \mathrm{~dB})$ 


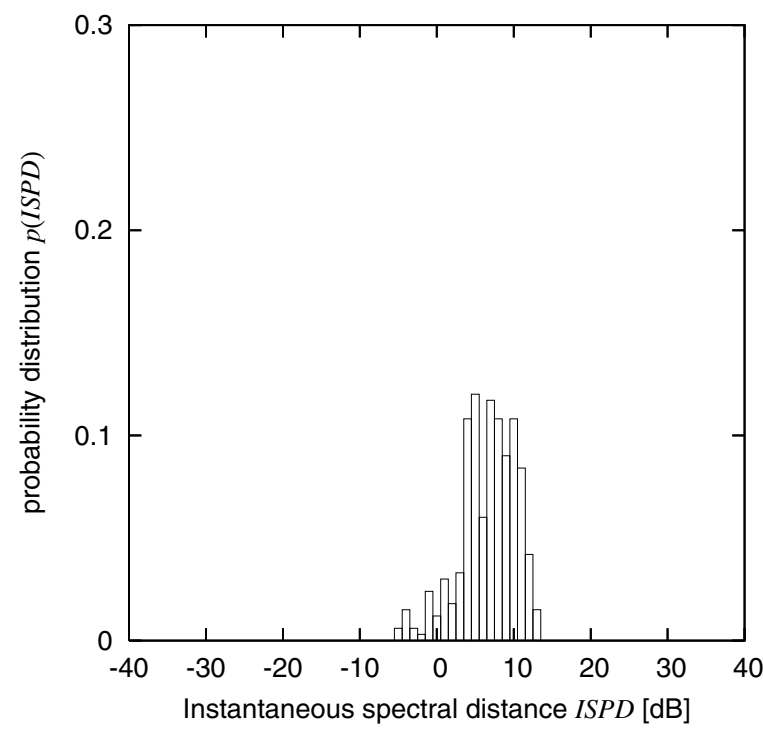

(a) Frequency filter: $\mathrm{C}$

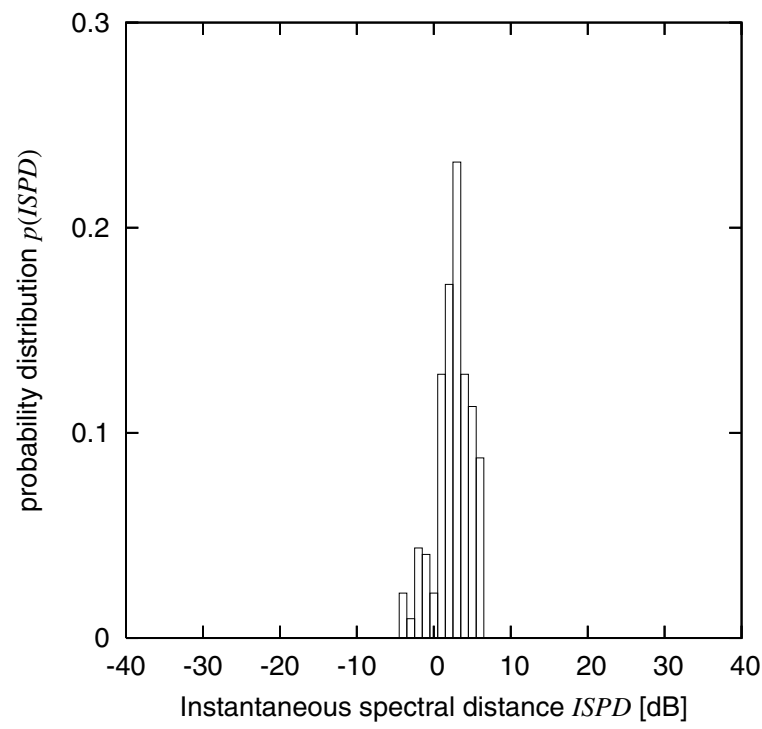

(b) Frequency filter: D

Fig. 10. Probability distribution on instantaneous spectral distance ((c) $62 \mathrm{~dB})$ 


\section{Conclusion}

This investigated how the listening scores of an audio signal and the psychological impressions related to speech audibility when listening to the audio signal under conditions of meaningless steady or fluctuating noise change when the frequency characteristics of hearing loss related to aging are taken into account. Specifically, psychological listening experiments by subjects with normal hearing were performed using artificial hearing impairments (frequency filters) that simulated hearing loss. Using the observed data obtained in psychological listening experiments, the relationships between WSPD and the listening scores of an audio signal and the psychological impressions related to speech audibility were established using regression models. Further, the effect of hearing loss due to factors such as aging on the listening scores of the audio signal and the psychological impressions related to speech audibility was predicted from the above relationships. Since the predicted values are in good agreement with the observed values, both the validity and the applicability of the proposed method were confirmed experimentally, and reasonable results were obtained.

Future studies should examine the following aspects of this research.

(1) Since the current study was limited to subjects with normal hearing who experienced artificial hearing impairment with frequency filter-simulated hearing loss, the applicability of the same method to situations where the subjects are actually hearing impaired persons should be confirmed. However, comparing the available data on hearing impaired persons with the results of our simulations of hearing impairment in this study, we can conclude that our study provides fundamental data to aid in determining whether the results of such psychological listening experiments conducted using normal-hearing subjects who experience artificial hearing impairment are as valid as those conducted on hearing-impaired subjects.

(2) Decreasing pure-tone audiometric thresholds were employed as hearing loss with increasing age. However, it is still necessary to consider other factors, such as loss of frequency selectivity and reduced temporal resolution in peripheral auditory deterioration.

\section{References}

Tamesue T. ; Yamaguchi S.; Saeki T. Psychological impressions and listening score while listening to audio signal under meaningless steady noise. Applied Acoustics Vol.64, No.4, 443-457.

Yonemoto K. Characteristics of CD for the evaluation of fitting condition with hearing aids (TY-89). Journal of Otolaryngology, Head and Neck Surgery Vol.11, No.9, 1395-1401.

ISO7029.Threshold of hearing by air conduction as a function of age and sex for otologically normal persons. 1984.

Yokouchi Y. Studies on the physiological hearing loss by age. Nippon Jibiinkoka Gakkai Kaiho Vol.67, No.9, 1307-1312.

Nakajima T. ; Maeda S. The application of speech transmission index (STI) as a measure of Japanese speech audibility. Proceedings of the Research Committee Meeting on Architectural Acoustics of the Acoustical Society of Japan No.AA-84-30, 1-8, 1984.

Kryter KD. Method for the calculation and use of the articulation index. The Journal of the Acoustical Society of America Vol.34, No.11,1692-1697, 1962.

Akaike $\mathrm{H}$. A new look at the statistical model identification. IEEE Transactions on Automatic Control Vol.AC-19, No.6, 716-723, 1974. 


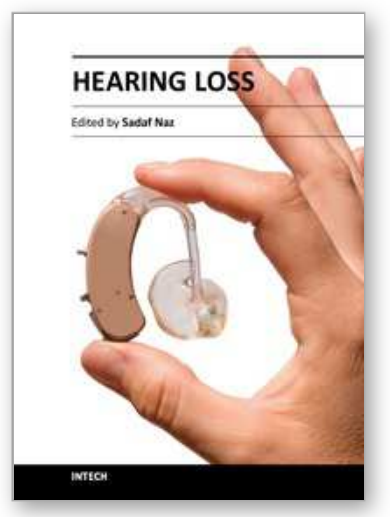

\author{
Hearing Loss \\ Edited by Dr. Sadaf Naz
}

ISBN 978-953-51-0366-0

Hard cover, 406 pages

Publisher InTech

Published online 28, March, 2012

Published in print edition March, 2012

Authored by 17 international researchers and research teams, the book provides up-to-date insights on topics in five different research areas related to normal hearing and deafness. Techniques for assessment of hearing and the appropriateness of the Mongolian gerbil as a model for age-dependent hearing loss in humans are presented. Parental attitudes to childhood deafness and role of early intervention for better treatment of hearing loss are also discussed. Comprehensive details are provided on the role of different environmental insults including injuries in causing deafness. Additionally, many genes involved in hearing loss are reviewed and the genetics of recessively inherited moderate to severe and progressive deafness is covered for the first time. The book also details established and evolving therapies for treatment of deafness.

\title{
How to reference
}

In order to correctly reference this scholarly work, feel free to copy and paste the following:

Takahiro Tamesue (2012). A Prediction Method for Speech Audibility Taking Account of Hearing Loss Due to Aging Under Meaningless Noise, Hearing Loss, Dr. Sadaf Naz (Ed.), ISBN: 978-953-51-0366-0, InTech, Available from: http://www.intechopen.com/books/hearing-loss/a-prediction-method-for-speech-audibilitytaking-account-of-hearing-loss-due-to-aging-under-meaningl

\section{INTECH}

open science | open minds

\section{InTech Europe}

University Campus STeP Ri

Slavka Krautzeka 83/A

51000 Rijeka, Croatia

Phone: +385 (51) 770447

Fax: +385 (51) 686166

www.intechopen.com

\section{InTech China}

Unit 405, Office Block, Hotel Equatorial Shanghai

No.65, Yan An Road (West), Shanghai, 200040, China

中国上海市延安西路65号上海国际贵都大饭店办公楼405单元

Phone: +86-21-62489820

Fax: +86-21-62489821 
(C) 2012 The Author(s). Licensee IntechOpen. This is an open access article distributed under the terms of the Creative Commons Attribution 3.0 License, which permits unrestricted use, distribution, and reproduction in any medium, provided the original work is properly cited. 